\title{
Women, communities, and the prevention of mother-to-child transmission of HIV: Issues and findings from community research in Botswana and Zambia
}

Laura Nyblade

Mary Lyn Field-Nguer

Follow this and additional works at: https://knowledgecommons.popcouncil.org/departments_sbsr-hiv

Part of the Community Health and Preventive Medicine Commons, and the International Public Health Commons

How does access to this work benefit you? Let us know!

\section{Recommended Citation}

Nyblade, Laura and Mary Lyn Field-Nguer. 2001. "Women, communities, and the prevention of mother-tochild transmission of HIV: Issues and findings from community research in Botswana and Zambia," Community Involvement in Initiatives to Prevent Mother-to-Child Transmission of HIV: A Collaborative Project. New York and Washington, DC: Population Council and International Center for Research on Women. 


\section{Women, Communities, and the Prevention of Mother-to-Child Transmission of HIV:}

Issues and Findings from Community Research in Botswana and Zambia

Laura Nyblade and Mary Lyn Field-Nguer,

International Center for Research on Women 


\section{(2) Population Council}

One Dag Hammarskjold Plaza

New York, New York 10017

telephone: 001 212-339-0500

fax: 001 212-755-6052

e-mail:pubinfo@popcouncil.org

www.popcouncil.org
I $($ RW

1717 Massachusetts Avenue NW, Suite 302

Washington, DC 20036

telephone: 001 202-797-0007

fax: 001 202-797-0020

e-mail: info@icrw.org

www.icrw.org

The Population Council is an international, nonprofit, nongovernmental institution that seeks to improve the well-being and reproductive health of current and future generations around the world and to help achieve a humane, equitable, and sustainable balance between people and resources. The Council conducts biomedical, social science, and public health research and helps build research capacities in developing countries. Established in 1952, the Council is governed by an international board of trustees. Its New York headquarters supports a global network of regional and country offices.

The International Center for Research on Women (ICRW), founded in 1976, is a private, nonprofit organization dedicated to improving the lives of women in poverty, advancing women's equality and human rights, and contributing to broader economic and social well-being. ICRW does this, in partnership with others, through research, capacity building, and advocacy on issues affecting women's economic, health, and social status in low- and middle-income countries. The Center's international, multi-disciplinary staff works from its headquarters in Washington, DC, and its office in New Delhi, India.

Copyright (C) 2001 by The Population Council, Inc. and the International Center for Research on Women

Any part of these papers may be copied or adapted to meet local needs without permission from the Population Council or International Center for Research on Women, provided that the parts copied are distributed free or at cost (not for profit) and that the source is identified. Any commercial reproduction requires prior permission from the Population Council or International Center for Research on Women. The Population Council and International Center for Research on Women would appreciate receiving a copy of any materials in which the text is used. 


\section{Foreword}

Mother-to-child transmission is the primary route of HIV infection in children under 15 years of age. Since the beginning of the HIV epidemic, more than 5 million children worldwide have been infected with HIV. Clinical trials in several countries have shown that mother-to-child transmission of HIV can be greatly reduced through administering a short, affordable course of antiretroviral therapy to pregnant women. These trials culminated in a recommendation by UNAIDS and its partners in the Interagency Task Team for the Prevention of Mother-to-Child Transmission that prevention of perinatal transmission should be a part of the standard package of care for HIV-positive women and their children. Moreover, it is quickly becoming clear that mother-to-child transmission prevention programs can enhance communities' understanding of and response to HIV. As a result, governments in Africa, Asia, and Latin America in collaboration with international and nongovernmental organizations have moved rapidly to improve antenatal care and incorporate interventions to prevent mother-to-child transmission of HIV into clinical and community-based care.

The acceptability, operational concerns, costs, and impact of this package of services on preventing mother-to-child transmission of HIV and on child morbidity and mortality are being addressed through a number of monitoring and evaluation activities. Advocates for issues concerning women's and children's health have raised equally important questions about how such interventions will be understood and received in the various communities in which they are becoming available, and how the interventions themselves can benefit from community input and involvement. In response the Population Council and the International Center for Research on Women (ICRW) initiated several activities to identify effective mechanisms for enhancing community involvement in efforts to prevent mother-to-child transmission. With support from Glaxo Wellcome's Positive Action Program and UNAIDS, the Population Council and ICRW analyzed the literature on community involvement in the introduction of health and other technologies at the local level and assessed community views on preventing mother-to-child transmission in Botswana and Zambia. 
This paper discusses research in Botswana and Zambia that showed gaps in community knowledge about HIV transmission, particularly from mother to child, and yielded insights into community perspectives about the barriers to using voluntary counseling and testing services; the stigma and fear associated with HIV; traditional norms on breastfeeding; and the role of family and community members in women's decisions to participate in programs to prevent mother-to-child transmission of HIV. A second companion paper, available on our website, offers lessons learned from the literature review of community involvement in earlier introductions of biomedical and other technologies. These lessons can guide appropriate and effective community involvement in the introduction of services for the prevention of mother-to-child transmission of HIV. A separate publication ("Community involvement in the prevention of mother-to-child transmission of HIV: Insights and recommendations"), also available on the Population Council website, offers our recommendations for strategies for community involvement, which we hope will encourage program planners to include community participation, education, and mobilization as critical program elements.

An intervention that addresses mother-to-child transmission of HIV is complex, yet it is one of the few biomedical interventions currently available for reducing the transmission of HIV that is feasible and affordable in resource-constrained settings. Placed within the framework of community involvement, it offers an enormous opportunity to improve HIV prevention and care. Successful interventions can influence how AIDS is perceived by the community, reduce stigma, and have an effect beyond the immediate prevention of perinatal transmission. Without community involvement, however, the opportunity to effect positive change may be squandered.

Naomi Rutenberg, Mary Lyn Field-Nguer, and Laura Nyblade 


\title{
Women, Communities, and the \\ Prevention of Mother-to-Child Transmission of HIV: \\ Issues and Findings from Community Research in Botswana and Zambia
}

\author{
Laura Nyblade and Mary Lyn Field-Nguer, \\ International Center for Research on Women
}

\section{EXECUTIVE SUMMARY}

More than one million children worldwide are infected with the HIV virus and are at great risk of dying from AIDS. The major cause of HIV/AIDS among children under 15 years of age is the transmission of HIV from mother to child during pregnancy, delivery, and breastfeeding. This problem is particularly prevalent in urban centers in southern Africa, where rates of HIV among pregnant women tested anonymously at antenatal clinics can be as high as 20-30 percent.

Clinical trials in several countries have shown that mother-to-child transmission of HIV can be dramatically reduced through the administration of a short course of zidovudine (AZT) to pregnant women. The United Nations Children's Fund (UNICEF), in collaboration with the Joint United Nations Programme on HIV/AIDS (UNAIDS) and the World Health Organization (WHO), has initiated pilot projects in 11 African countries to provide mothers with both a short course of AZT and information on alternatives to breastfeeding. However, these projects - in large part due to time constraints-have been conducted with little consultation with or feedback from residents of the targeted communities.

For this reason, in 1999 Glaxo Wellcome and UNAIDS jointly funded two formative research studies in Botswana and Zambia on the perspectives, needs, and preferences of women and communities regarding the means to prevent the transmission of HIV from mother to child. Carried out by the International Center for Research on Women (ICRW) in collaboration with in-country partners, the studies sought to obtain information and 
data that could be used to improve the effectiveness and acceptability of messages and services for prevention of mother-to-child transmission at the community level. Toward this end, focus-group discussions were held with residents of one community in each country. In-depth interviews were also conducted with women in Botswana, where a prevention program was launched in two cities in 1999. Preparations for establishing a similar program in Zambia are underway.

The research revealed that levels of knowledge about transmission and prevention of HIV and prevention of mother-to-child transmission ranged widely among residents of Bontleng, Botswana. In contrast, residents of Keemba, Zambia, were well informed about both the transmission and prevention of HIV, but knew little about mother-to-child transmission because there was no prevention program. In both countries, the main source of information about health issues in general, and HIV/AIDS in particular, was talks given at antenatal and well-child clinics. Since men and community elders do not usually visit clinics, they know less than women do about HIV/AIDS and mother-to-child transmission.

In addition, members of both study communities emphasized that people living with HIV/AIDS suffer from stigma, discrimination, and isolation, all of which deter many residents from being tested for HIV. With regard to mother-to-child transmission specifically, strong cultural norms support breastfeeding and prevent HIV-positive women from considering other infant feeding choices.

By listening to individuals, it is possible to gain insight into how to design and deliver interventions that can be used widely and be effective in saving the lives of adults, children, and infants. The studies underscored how local communities can benefit from the research process by gaining knowledge about HIV/AIDS and mother-to-child transmission and confronting difficult issues. The primary conclusion of the studies is that programs have an urgent need for the information and perspectives that emerge from community dialogue about HIV/AIDS and prevention of mother-to-child transmission of HIV. 
The studies yielded several recommendations. In the area of community education, it became clear that efforts should emphasize participant feedback and quality control mechanisms in order to ensure that community members understand the information they receive on HIV, mother-to-child transmission of HIV, and related issues. Efforts should be made to ensure that service providers understand the relative (rather than absolute) effectiveness of AZT in preventing HIV transmission, the links between mother-to-child transmission and breastfeeding, and the potential risks of other infant feeding methods.

In addition, counseling services should be extended beyond antenatal clinics so that a broad community audience can be reached. Men and elders in particular should be targeted with information on and opportunities to discuss HIV and mother-to-child transmission. Support services should also be increased for the families of people living with HIV/AIDS in order to reduce the burden of care and encourage community residents to seek testing and counseling.

\section{BACKGROUND}

To date, AIDS has caused the deaths of more than three million children worldwide, and more than one million more are infected with HIV (UNAIDS 2000). Among children under 15 years of age, the major cause of HIV/AIDS is the transmission of HIV from mother to child during pregnancy, delivery, and breastfeeding. In the absence of preventive measures, the risk that an infant of an HIV-positive mother will become infected with the virus ranges from 25 to 35 percent in developing countries (UNAIDS and WHO 1999a).

Although Africa accounts for only 10 percent of the world's population, 90 percent of all HIV-infected people live in the region (UNAIDS 2000). In urban areas of southern Africa, rates of HIV infection among women attending antenatal clinics can be as high as 
20-30 percent (UNAIDS and WHO 1999b). Until recently, strategies to prevent infants from becoming infected with HIV have consisted primarily of recommendations for preventing primary infection of the mother prior to and during pregnancy as well as providing information about breastfeeding. Other strategies have included use of contraception to prevent pregnancy or pregnancy termination where this option is legal and available. In addition, there are specific guidelines on practices to reduce the likelihood of transmission during labor and delivery.

In an increasing number of countries, however, additional options for preventing motherto-child transmission of HIV are now available. Recent trials in Burkina Faso, Côte d'Ivoire (Dabis et al. 1999), and Thailand (Shaffer et al. 1999) have shown that administering a short course of zidovudine (AZT) to pregnant women reduces the risk that HIV will be transmitted from a mother to her child to below 10 percent-a 50percent reduction below normal transmission rates-as long as the mother does not breastfeed. More recently, a study in Uganda revealed a similar effect when nevirapine was given to the mother at the onset of labor and to the baby 72 hours after birth (Guay et al. 1999).

\section{THE NEED FOR QUALITATIVE RESEARCH}

As more women throughout Africa become infected with HIV prior to and during pregnancy, prevention of transmission of the virus to infants has become an increasingly important component of AIDS programs in many countries. Following a 1998 meeting, the United Nations Children's Fund (UNICEF), in collaboration with the Joint United Nations Programme on HIV/AIDS (UNAIDS) and the World Health Organization (WHO), initiated pilot projects in 11 African countries to provide mothers with both a short course of AZT and information on alternatives to breastfeeding. It was soon observed, however, that these projects-in the context of a raging epidemic and time constraints-were being conducted in a climate of little consultation with or feedback from residents of the targeted communities. 
It is critical that communities have a voice in solving the health problems that affect them. This is especially true when introducing programs that can have an enormous impact on the lives of women, their partners, and their extended families. The benefits of many technologies (prescription drugs and a required blood test in the case of mother-tochild transmission) are often overshadowed by conflicting community norms, values, and beliefs. The issues surrounding mother-to-child transmission are particularly challenging because of the complexity of the HIV transmission process and the stigma associated with HIV/AIDS. Because mother-to-child transmission is a sensitive topic and the cultures and communities in which it is a concern are diverse, talking to women and other members of a community is a vital step in preventing HIV transmission to infants.

\section{RESEARCH OBJECTIVES}

The studies described in the following pages gathered information on the perspectives, needs, and preferences of women and communities regarding mother-to-child transmission of HIV. Research was conducted between October 1999 and May 2000 in Botswana and Zambia.

The central goal was to obtain information and data that could be used to improve the effectiveness and acceptability of messages and services for prevention of mother-tochild transmission at the community level. To achieve this goal, investigators documented the beliefs, views, wishes, and needs of women and their communities regarding mother-to-child transmission; counseling and testing; treatment; and infant feeding options.

Specifically, the investigators sought insight into what women and communities know about mother-to-child transmission and whether they define it as a problem. They also sought an answer to why women often decline to participate in voluntary counseling and testing - a critical first step in programs to prevent mother-to-child transmission of HIV. The research was designed to provide insight into the community context in which such prevention programs exist and to contribute to the design of successful strategies. 


\section{STUDY PARTNERS}

ICRW worked with the Society of Women Against AIDS in Africa/Botswana Branch, a nongovernmental organization established in 1995 to provide HIV/AIDS education, support, and prevention programs to women throughout Botswana. The society has experienced an increased demand for information about mother-to-child transmission. In turn, the society has needed data about community beliefs, perceptions, and requirements related to mother-to-child transmission in order to improve the design and focus of its education efforts.

In Zambia, ICRW worked with the Mother-to-Child Transmission Research Team of the National Mother-to-Child Transmission of HIV Working Group. Appointed by the minister of health in August 1998 to offer technical assistance and advice to the government's central board of health, the working group conducts research and develops country-specific interventions and strategies related to the mother-to-child transmission of HIV. ${ }^{1}$

\section{STUDY SITES}

Although in the same region of Africa, Botswana and Zambia differ in important ways. In terms of gross domestic product, literacy rate, and health infrastructure, Botswana is significantly better off than Zambia. At the beginning of the research study, the government of Botswana was already providing prevention services to pregnant women through a program established in April 1999, whereas Zambia was preparing to do so. ${ }^{2}$

\footnotetext{
${ }^{1}$ The membership of the working group is diverse in order to reflect the various populations that are involved in issues related to HIV. Members include people living with HIV, HIV counselors, doctors, nutritionists, biologists and other scientists, policymakers, and bilateral and multilateral agencies.

${ }^{2}$ In 1999 Botswana launched pilot projects aimed at preventing mother-to-child transmission in all government health clinics in the cities of Francistown and Gaborone. This was accomplished by training health workers in counseling and obstetric practices; strengthening systems at laboratories; providing supplies to conduct HIV tests; and purchasing and distributing AZT and breastmilk substitutes. These activities were implemented collaboratively by the government of Botswana, UNICEF, and the Harvard
} 
Botswana provided an opportunity to learn from and explore the experiences of women participating in a program to prevent mother-to-child transmission of HIV. In contrast, the study in Zambia allowed researchers to gather data that could contribute to the design of a new program.

In Botswana, nearly 36 percent of adults are now infected with HIV, more than a tripling of the adult prevalence since 1992 (UNAIDS 2000). In 1998 the median rate of HIV infection among women attending antenatal clinics was 43 percent in urban areas and 30 percent in nonurban areas (UNAIDS 2000). The study focused on Bontleng, a lowincome urban community in the city of Gaborone in southeast Botswana, where residents have access to the government's program to prevent mother-to-child transmission through a clinic with excellent infrastructure.

As in most of sub-Saharan Africa, HIV/AIDS is a rapidly growing problem in Zambia. More than one in four adults living in cities and one in seven adults in rural areas is infected with HIV (UNAIDS 2000). Heterosexual contact and mother-to-child transmission account for most new HIV infections in the country. In 1998 median rates of HIV infection among women tested at antenatal clinics were 27 percent in urban areas and 14 percent in nonurban areas (UNAIDS 2000). ${ }^{3}$

Before the study was launched, the Zambian mother-to-child transmission working group had selected three sites for implementing the UNICEF pilot program and had already conducted formative research at one site. The group requested that ICRW, in collaboration with the working group, conduct research in Keemba, in the south-central Monze District, with the intention of feeding data directly into the development of a broad communication strategy for a mother-to-child transmission prevention program. Residents of Keemba, a rural community, have access to basic clinic services. At the

\footnotetext{
AIDS Institute. Zambia recently launched a program to prevent mother-to-child transmission in Lusaka and is expanding it to other pilot sites this year, including Keemba.

${ }^{3}$ In comparison to Botswana and Zambia, several African countries have much lower rates of HIV. For example, in Ghana in 1998, the median prevalence among women tested at antenatal clinics was under 4 percent in both urban and nonurban areas (UNAIDS 2000).
} 
onset of the study, several meetings with community elders had been held to discuss the establishment of a program to prevent mother-to-child transmission of HIV.

\section{METHODOLOGY}

Focus-group discussions were the principal method of collecting data in both countries. In addition, several in-depth interviews were conducted with women in Botswana to ascertain their experiences with the existing prevention program.

All moderators and interviewers were trained to use focus-group discussions and in-depth interview guides developed collaboratively by ICRW and the in-country research partners. The guides were pretested, and text analysis was used to analyze data from both communities. Methodological aspects specific to the work in Botswana and Zambia are described below.

The study was conducted in only one location in each country. As a result, contrasting findings between the countries may be attributable to urban-rural differences to at least the same degree as to national or cultural variations. The findings would have been better triangulated if the study methodology had included additional methods. However, the studies were designed to increase understanding of the issues surrounding prevention of mother-to-child transmission in relation to women and their communities, and the results reflect the views of many local residents. Although the same views are likely to be found in other communities, a study conducted on a national scale would certainly yield important variations.

\section{Botswana}

Moderators conducted a total of 11 focus-group discussions with 8-12 participants in each group. Participants were those who are most closely affected by programs to prevent mother-to-child transmission and those who play a significant role in shaping community norms and supporting individuals in making decisions related to prevention of mother-tochild transmission. Because of the complexity and sensitivity of the issues involved, 
discussions were sometimes extended to two sessions. In several cases, it was difficult to assemble the same group of people twice, thus prompting moderators to involve different participants for the second round of discussions.

The Botswana sample included:

- breastfeeding women between ages 18 and 30;

- breastfeeding women 30 years of age and older;

- pregnant women between ages 18 and 30;

- men between ages 18 and 30;

- men 30 years of age and older; and

- male and female community elders.

Various methods were used to select focus-group participants. The research study was announced and described to women attending antenatal clinics and well-child sessions at Bontleng Clinic, and a request was issued for volunteers to attend discussions in the evenings at the Bontleng Community Center. Men were selected through male contacts in the community, who announced the study in neighborhoods and asked fathers to volunteer. Community elders were brought together by both the local councilor (politician) and the chairperson of the village development committee. Focus-group discussions were held at a time and place that were convenient for the participants, usually in the evenings or on the weekends at local gathering places.

The research team worked with local clinic nurses to identify women who had participated in programs to prevent mother-to-child transmission of HIV and were willing to be interviewed. Ten in-depth interviews were then conducted to learn why women had or had not chosen to participate and how they were responding to the programs (see Table 1). As expected, finding women who were willing to be interviewed was extremely difficult because of the mobility of the population between urban and rural areas and within Gaborone, busy work and home schedules, and the sensitive nature of mother-tochild transmission and HIV/AIDS. Because many women did not want to be interviewed, the composition and number of interviews in the final sample differed from what was 
originally planned. ${ }^{4}$ None of the women agreed to have her interview taped, and one terminated the interview before it was completed.

In addition, a semistructured group interview was conducted with family welfare educators based at clinics and working in the community, and two semistructured individual interviews were conducted with nurse-midwives who provide counseling for the prevention program. ${ }^{5}$

Table 1. In-depth interviews conducted in Botswana

\begin{tabular}{|l|c|}
\hline $\begin{array}{l}\text { Level of participation in program to prevent } \\
\text { mother-to-child transmission }\end{array}$ & $\begin{array}{c}\text { Number of } \\
\text { women }\end{array}$ \\
\hline Refused HIV testing & 2 \\
\hline Wanted to consult partner first; never returned & 1 \\
\hline Accepted HIV test; never returned for results & 2 \\
\hline Was tested; got results (HIV-negative) & 1 \\
\hline Was tested; took AZT; chose to breastfeed & 1 \\
\hline Was tested; took AZT; chose to formula feed & 3 \\
\hline
\end{tabular}

\section{Zambia}

Moderators conducted 15 focus-group discussions with 8-12 participants in each. In order to address sensitive issues and to allow the maximum time for discussion, the discussion guide was divided into two sections to be addressed in separate sessions. Thirteen focus-group discussions were held in Keemba near the health center; another two were conducted at Chuungu village at an outreach health post where clinic staff conduct antenatal, well-child, and outpatient clinics once a month. Because of time constraints, the groups in Chuungu and the community elders were interviewed using a condensed version of the discussion guides.

\footnotetext{
${ }^{4}$ See Tlou et al. (2000) for details.

${ }^{5}$ The study remained focused on the perspectives of women and their communities. An evaluation of the pilot programs conducted in June 2000 by the Ministry of Health/Family Health Division provides a comprehensive account of provider perspectives on the program.
} 
The Zambia sample included:

- breastfeeding women in Keemba (split into two groups roughly below and above the age of 30);

- pregnant women in Keemba (split into two groups roughly below and above the age of 30);

- men in Keemba (split into two groups roughly below and above the age of 30);

- pregnant women of all ages in Chuungu;

- breastfeeding women of all ages in Chuungu; and

- male community elders of all ages in Keemba (i.e., ministers, church elders, community health workers, and village health committee members).

Female focus-group participants were selected by clinic staff from the pool of women who attended antenatal clinics or maternal and child health programs at the health center on the days that focus groups were scheduled. Women were asked to volunteer, and information about their age and residence was collected. The study team then randomly selected participants based on their place of residence to ensure that the women selected came from different parts of the Keemba clinic catchment area. Participants in the Chuungu focus groups were recruited by a community health worker from a random list of women registered for antenatal and well-child clinics at the health post. Men were selected through announcements about the study made at local churches asking those interested in participating to report to the Keemba health center. ${ }^{6}$

\section{FINDINGS AND DISCUSSION}

This section synthesizes, compares, and contrasts key findings from the two communities studied (see Box 1). ${ }^{7}$ First, findings on the context in which women make decisions about

\footnotetext{
${ }^{6}$ While this method of selection is potentially biased toward church members, staff at the health center confirmed that a very high percentage of male residents of the community do attend church.

${ }^{7}$ Detailed information is available in the study reports from each country (Bond, Ndubani, and Nyblade 2000; Tlou et al. 2000).
} 
prevention of mother-to-child transmission are reported. The data in this section present information related to the perceived extent of HIV/AIDS, knowledge and beliefs about HIV/AIDS, sources of information about HIV/AIDS, care and support for people living with HIV/AIDS, and knowledge and beliefs about mother-to-child transmission and its prevention.

Second, community residents' perceptions of and participation in the central components of current and planned prevention programs are presented, including counseling and testing, drug treatment during pregnancy, and infant feeding. In this section knowledge, perceptions, and desires of study participants in relation to these issues are discussed. 


\section{THE COMMUNITY CONTEXT}

Participation in programs to prevent mother-to-child transmission forces pregnant women to think about and make decisions on such complex and sensitive issues as HIV testing and counseling, drug treatment during pregnancy, and alternative infant feeding practices. Pregnant women do not face these issues in a vacuum, however; partners, family, and community members influence the decisions that pregnant women make about each of these issues.

The choices a woman makes have potentially far-reaching implications for her emotional and physical health, the well-being of her child, her relationship to the father of her child, broader familial relationships, and how she is viewed and treated within the community. The design and implementation of effective programs that allow for voluntary participation should therefore be based on an understanding of a woman's circumstances and of the decisions she makes, and how significant people in her life influence and react to those decisions.

Similarly, the overall context of HIV/AIDS in the community is an important determinant of the need for and potential success of a program to prevent mother-to-child transmission. In order to determine what elements should be included in programs, it is crucial to understand what communities know about HIV/AIDS and mother-to-child transmission; where they obtain relevant information; how they view, treat, and care for people living with HIV/AIDS; and what they think about voluntary counseling and testing, using drugs during pregnancy, and infant feeding. Findings related to these aspects are discussed below.

\section{Perceptions of HIV/AIDS Prevalence}

All of the focus groups defined HIV/AIDS as widely prevalent in their communities, although there were differences between urban Botswana and rural Zambia with regard to recognition of the personal and community-wide impact of the disease. 
In Botswana, estimates of HIV/AIDS prevalence by participants in the focus-group discussions ranged from 30 to 90 percent of community residents. However, the majority also claimed that they had little personal knowledge of people living with HIV/AIDS and did not consider HIV/AIDS to be an overwhelming problem in their community. As one breastfeeding woman stated:

Personally, I don't know what people are talking about when they mention this disease AIDS. I have always heard about it, but I can't actually say that I have seen someone like that. What I have seen is someone that loses a lot of weight and later on has a continuous running stomach.

Thus, while AIDS or the identification of a given illness as indicative of AIDS was not commonly acknowledged, a progression of symptoms that could be indicative of AIDS was noted. In the words of a Botswanan man:

When it starts they never get healed of flu. They always have diarrhea. They also complain about aches in their legs, then it is TB. They take a lot of tablets but they continue losing weight. They change color, they look like a pot, they become so black that even body lotion doesn't seem to help. They are always vomiting.

Not "knowing" anyone with HIV/AIDS in Botswana was also discussed in conjunction with the perceived secrecy surrounding people living with HIV/AIDS, as evidenced in this statement by a male elder:

When people have HIV, it is always a secret. It will just remain a rumor that soand-so has HIV, but it will never be verified whether it is true or not. They only mention AIDS when someone is already dead.

In addition, because many of the symptoms associated with HIV/AIDS are also characteristic of other illnesses, participants in the focus groups made statements such as 
the following remark by a Botswanan man: "We can't identify such people [people living with HIV/AIDS] because mostly we all look the same."

In contrast, focus-group participants in Zambia viewed HIV/AIDS as an overwhelming problem. For example, male participants in Keemba noted that such large numbers of community members are dying of HIV/AIDS that, in the words of one, "There isn't a Sabbath day which can pass without witnessing two or three deaths" and that large numbers of other people are severely ill and "just waiting for the day." The need to care for an increasing number of orphans was also associated with HIV/AIDS, as well as the fact that even healthy-looking people may be infected.

Focus-group participants in Zambia often felt overwhelmed by HIV/AIDS to the point of feeling hopeless. In the words of a Zambian man, "It is beyond our control, so we have given up and stopped fearing."

Messages that inspire hope must be included in programs to prevent mother-to-child transmission of HIV in Zambia. In Botswana, on the other hand, messages may need to focus primarily on convincing community members that both mother-to-child transmission and HIV/AIDS are, in fact, growing concerns that must be addressed.

\section{Knowledge and Beliefs About HIV/AIDS}

In both study communities, women were generally better informed than men about HIV/AIDS, in particular with regard to factual details on modes of transmission and methods of prevention. An unexpected finding was that residents of rural Zambia had greater knowledge about HIV/AIDS than their counterparts in urban Botswana. In Zambia, knowledge was uniformly high among all the sample groups, while in Botswana it varied widely and many participants had some, but not complete, knowledge regarding transmission and prevention. ${ }^{8}$

\footnotetext{
${ }^{8}$ It is not clear why this pronounced difference between Zambia and Botswana exists. Such variation is a critical area for future investigation.
} 
As mentioned, the level of community knowledge about HIV/AIDS influences the context within which women make decisions about prevention of mother-to-child transmission, and in turn the design and implementation of appropriate messages. The lack of knowledge regarding transmission and prevention leads directly to the widespread fear of contracting HIV from casual contact with or care of an infected person, which in turn fuels the stigma and social isolation felt by those presumed to be ill with AIDS. Pregnant women trying to decide whether or not to be tested for HIV are influenced by the negative community attitudes toward individuals suspected of having AIDS. In addition, if a community tends to blame women for the spread of HIV, women will be even more reluctant to take an HIV test.

All focus groups in both communities defined multiple partnerships outside marriage or sanctioned relationships as the major cause of HIV transmission. Those who have the virus may therefore be assumed to have engaged in this type of behavior, an attitude that may often fuel prejudice and stigma. With regard to attitudes toward multiple partnerships, a subtle difference observed between the two communities may have implications for prevention of mother-to-child transmission.

While focus-group participants in Botswana recognized that both men and women are "promiscuous," men talked more about how, in the words of one, "Girls change partners like they are changing dresses" and "Women get [HIV] because they don't respect their husbands." Not surprisingly, women discussed male "promiscuity" more often, and in stronger language, than did men or elders. One breastfeeding participant stated emphatically, "There is no man who doesn't cheat."

In contrast, male and female focus-group participants in Zambia acknowledged that both men and women engage in unsanctioned sex, although for different reasons. Both male and female participants described women more sympathetically, saying that they engage in unsanctioned sex because their economic circumstances offer them little choice. As explained by a pregnant woman in Keemba in reference to local migrant workers, "In the 
presence of money from these contractors, it is difficult to refuse sex from them." On the other hand, men were viewed as having an innate need for multiple sex partners and as lacking sexual control. In the words of another pregnant participant, "Men go for variety. There is a Tonga phrase that says you do not eat one type of food everyday, such as pumpkin leaves with groundnuts or okra all the time."

Thus, in Botswana participants tended to focus on and blame women's behavior, while in Zambia, men were also held responsible. The fact that men in Zambia recognized their contribution to the spread of HIV suggests their potential readiness to support prevention efforts, a trend that could be harnessed to improve programs in the future.

\section{Information About HIV/AIDS}

In both communities, study participants cited several sources of HIV/AIDS information. Women indicated that they received most information from health workers at the local clinic, specifically in the form of health talks during antenatal clinics and well-child sessions. While other sources were mentioned in both communities, it became clear that clinics are the main sources of information.

Focus-group participants also revealed that residents of both communities perceive that gender affects the ability to gain information, since women of childbearing age access health facilities far more often than do men and elders, who consequently are less informed and feel excluded. As a breastfeeding participant from Zambia explained, "Our husbands are not taught as we are about HIV/AIDS."

Nonetheless, men and elders play a significant role in women's lives and influence decisions on matters such as HIV testing and infant feeding. Women, men, and elders in both study communities expressed a desire to bridge the gender-related information gap, indicating the possibility of developing and implementing creative strategies to communicate vital information on HIV/AIDS and mother-to-child transmission to husbands, partners, and other community residents. 


\section{Care and Support of People Living with HIV/AIDS}

In both Botswana and Zambia, focus-group participants voiced the expectation that immediate family will always care for people living with HIV/AIDS, possibly with assistance from extended family members. In Keemba, Zambia, a man explained, "You keep them in the house because they are part of the family," while a pregnant woman in Chuungu said, "Families must depend on themselves." In Botswana, a breastfeeding woman said, "The person is my family so I cannot desert him."”

Focus-group discussions in Botswana, however, generated debate and elucidated strongly differing opinions about the extent of care and support that people living with HIV/AIDS would receive from their extended families. Some felt that families would always care for people living with HIV/AIDS, while others felt that if relatives knew that HIV was the cause of the person's illness, the relatives would no longer provide care. One breastfeeding woman believed, "They [relatives] may be helping in the beginning, but when they hear that the person is suffering from AIDS, they disappear."

In addition to the stigma attached to HIV/AIDS, focus-group participants cited the perceived breakdown of the extended family and being in an urban setting as contributing factors to lack of care and support to people with HIV/AIDS. As a young man explained, “These days, relatives don't help each other like they used to. If you get HIV, no one in the family seems to care about you and they want to distance themselves from you."

In Botswana, other possible reasons for the perceived reluctance of relatives to care for a person with HIV/AIDS fell into three main categories, as illustrated by the following quotes from study participants.

\footnotetext{
${ }^{9}$ It should be noted that, while formal support structures exist in many areas to help people with HIV/AIDS and their families (in particular, home-based care groups), these are not well-developed in either of the study communities. Consequently, participants in both communities were not familiar with such support options, and only a few mentioned them after direct probing from the moderators.
} 
Blame. A breastfeeding woman said, "I don't think they [family members] are interested [in care and support] because sometimes the disease attacks a young person after the parents or elders have tried to talk to him/her [about sexual behavior], but to no avail."

Fear of contagion. A breastfeeding woman stated, "Even when a person knows that the person is family, they don't help care for him. All they are thinking about is that if they help that person they are also going to get infected."

Burden of care. The female focus groups discussed the emotional stress of caring for a patient when death is the only possible outcome and their feelings of hopelessness and emotional exhaustion. ${ }^{10}$ In the words of one breastfeeding woman, "In the long run even family members lose hope and feel helpless toward the patient." It is also physically difficult to care for someone who is very ill, as a young pregnant woman indicated: "The relatives never used to come to help. ... when this sister of mine was sick and had diarrhea, I used to go to the clinic to get gloves. It is very difficult when someone has diarrhea and is always vomiting."

Although the burden of care associated with the need to support people living with HIV/AIDS was discussed in Zambia, few people questioned that families would be responsible. However, some participants described parents as being angry about having to look after chronically ill grown children at a time when economic resources are increasingly limited. Although little expectation was expressed in Botswana that neighbors or the larger community would provide help, in Zambia the community was described as assisting families caring for people living with HIV/AIDS with such tasks as cooking food and drawing water.

Information about the care of people living with HIV/AIDS enhances understanding of the issues that pregnant women face in making decisions about prevention of mother-tochild transmission of HIV. For example, knowing that potential sources of support for

\footnotetext{
${ }^{10}$ The fact that only one male participant mentioned the strenuous aspects of care most likely reflects the fact that women are almost always the exclusive caregivers for the ill.
} 
people with HIV/AIDS exist can persuade an individual to get an HIV test. However, focus-group discussions in both communities produced an undercurrent of fear that if HIV was the confirmed (as opposed to the suspected) cause of an illness, care and support might be given less readily, or even withdrawn, by family and community members. This fear is probably based on the perception that people with HIV/AIDS are blamed for their own illness, as well as on the harsh reality of communities having to decide whether to allocate limited resources to care for a patient who has little hope of getting better.

\section{Knowledge and Perceptions of Mother-to-Child Transmission of HIV}

Focus groups in both communities perceived HIV infection among infants to be prevalent. In Botswana, participants expressed the sense that the problem is largely "invisible." Reasons included the lack of clearly identifiable symptoms and the short life span of HIV-infected babies. As summarized by a breastfeeding participant:

They look fresh [fat] and they die fresh. So we don't know whether it was HIV or just another disease. The babies don't usually struggle like adults. They just cough a little and then pass on, so it is very difficult to know whether it was HIV or not.

In both study communities, participants expressed a general understanding that HIV can be transmitted from mother to child, but knowledge about the points during pregnancy, delivery, and breastfeeding when mother-to-child transmission can occur was limited. Participants in Botswana knew more about the details of transmission than their counterparts in Zambia, although most focus groups mentioned only one or two of the three possible avenues. In Zambia, participants in only two focus groups mentioned transmission through breastmilk, and participants in three were aware of the possibility of transmission through razor blades, which are used by traditional birth attendants to cut a baby's umbilical cord. 
In Botswana, only one respondent, a man, stated that it was possible for an HIV-infected mother to have an HIV-negative baby. The overall consensus in the focus groups in both communities was that if the mother was HIV-positive, the baby would inevitably be so, too, as indicated by two pregnant participants, from Botswana and Zambia respectively:

The baby feeds on the birth supply from the mother during pregnancy. If the mother's blood has the HIV virus, it means that the baby will get it.

The blood that has made the child has the infection and the child will be born with it.

\section{Prevention of Mother-to-Child Transmission of HIV}

At the start of this study, the government's prevention program had been operating at the local health center in Bontleng, Botswana, for seven months, while prevention program services were not yet available at the research site in Zambia. Consequently, most Botswanan participants (particularly women) were aware that it was possible to prevent mother-to-child transmission through a program at the clinic. Many were also familiar with the HIV testing and drug components of the prevention program; and while they were aware of alternatives for feeding infants and provision of infant formula, they mentioned these less frequently. According to a young breastfeeding woman:

At the clinic they ask you whether you have an interest in checking for the HIV virus so that if you have the virus in your blood they can give you AZT to prevent transmission from mother to child.

Men and community elders, who play influential roles in women's lives, were largely unfamiliar with specific components of the prevention program. They often expressed skepticism about the effectiveness of the program, which indicated that they are not being reached by education efforts or receiving information about the transmission process. As a male elder said: 
The womb is attached to the mother and this womb is blood, which comes from the mother to feed the baby. That is why we don't believe that this so-called treatment $[\mathrm{AZT}]$ would be able to separate the baby from the mother's womb. How will this treatment avoid contact with the infected mother to keep the baby free from infection?

In Zambia, several preliminary meetings had been held with local leaders to discuss proposals for future prevention programs. Through comments made in the focus-group discussions about pregnancy and HIV and about counseling and testing during pregnancy, it became clear that some of the information from these meetings had been communicated to the wider population. For example, one man explained that women would be happy to be tested if they were offered a medication to prolong life. Several women from Keemba and Chuungu made similar comments, including the following:

Maybe agree [to testing] because [they] will help you if you have a disease [HIV].

Tablets protect a bit so live longer.

All of us could tell our husbands if we all had blood taken and there were drugs to protect the baby.

Such statements indicate that information can spread quickly through a community and generate a demand for more information. However, information must be carefully presented. Some responses from study participants hinted at the expectation or understanding that drugs also help mothers, which underscores the need for very clear messages and ongoing monitoring of how a community understands the information and ideas provided by a program.

Focus-group participants in Botswana supported the prevention program because of the benefits to the child and the potential for saving a child's life. Some participants, however, were concerned about what would happen to a child whose life was saved, but whose mother was going to die. As one breastfeeding participant explained, "It is a good program for the baby. But in the process a pregnant woman will be thinking-you know, 
I am going to die anyway, my baby might live, but if I die what is the point because there will be no mother to raise my baby."

Similarly, members of a male focus group expressed concern that the government was focusing on curing babies but not mothers, and some asked, "Why don't we get medication that will cure both the baby and the mother?" In addition, men expressed the belief that pregnancy hastens the onset of AIDS and death. In the words of one male respondent, "If one has the virus and gets pregnant, the virus will increase in her body. The person may end up dying before her time."

\section{COMPONENTS OF PROGRAMS TO PREVENT MOTHER-TO-CHILD TRANSMISSION OF HIV}

\section{Voluntary Counseling and Testing}

Offering voluntary counseling and testing in the context of antenatal clinic services is a relatively new phenomenon in Botswana and is currently not an option in Zambia. In addition, locally available, freestanding voluntary counseling and testing services (i.e., those not connected to a medical facility) are not available in Keemba, Zambia and, until recently, were available at only one site in Gaborone, Botswana run by the Red Cross.

In Zambia, focus-group participants knew that it was possible to get tested for HIV at the Monze Mission Hospital as part of a diagnostic process to determine the cause of an existing illness, but thought that health personnel would not inform patients if they tested positive. In the words of a breastfeeding woman, "We are tested at the hospital but not told that we have HIV. Instead we are told that we have TB. They do not tell us that it is HIV because they are worried that we would commit suicide. They tell us that it is TB of the bones."

Although one voluntary counseling and testing service is available in Gabarone, residents of Bontleng and Keemba had no concept of seeking voluntary counseling and testing or 
of voluntarily choosing to know one's HIV status while still healthy. In both communities, participants thought that few people would seek counseling and testing on their own and that those who did would certainly not voluntarily disclose an HIV-positive test result. As a breastfeeding woman in Botswana said, "If I do test positive I will keep my status a secret. This way we do not know that so-and-so has AIDS." And in the opinion of a man in Zambia, "It is not a disease that people would announce like malaria. ... It is not treated like any other disease."

Given this lack of familiarity with voluntary counseling and testing, focus-group discussions centered largely on the hypothetical situation of "if testing were available," rather than on testing as part of antenatal clinic services. Questions asked about testing in the context of antenatal care, in particular regarding decisionmaking by women, did not generate much discussion because focus-group participants did not differentiate between pregnant women and others with regard to voluntary counseling and testing. Although voluntary counseling and testing offered within an antenatal clinic setting differs somewhat from that provided at freestanding centers, it is important to understand what women and communities think about counseling and testing in general in order to get a sense of how women might respond to the offer of testing during a visit to an antenatal clinic. This information is especially helpful in settings where women, their partners, and the community are largely unaware that HIV testing is available through an antenatal clinic, and can be used as the basis for developing messages about voluntary counseling and testing in general and in the antenatal clinic system in particular.

In both communities, the most frequently mentioned reason for seeking voluntary counseling and testing was to determine whether a chronic illness was indeed caused by HIV. A young man in Botswana stated, "Many people go for a test when they are sick. But when they are fit, like me, it is rare for a person to check." Because a person who falls ill is often already suspected of being HIV-positive, the negative social consequences of disclosure that a person has used voluntary counseling and testing - and has therefore potentially received positive test results-may be less severe. 
Although focus-group participants in both communities mentioned some benefits of voluntary counseling and testing, discussion focused mainly on the drawbacks. In both communities, the most positive aspect mentioned was that it could help people change their lifestyles, which could increase life expectancy in the case of a positive test and could help people avoid infection if their test results were negative. Many participants expressed this view. For example, a breastfeeding woman in Botswana said that voluntary counseling and testing "is important because if my attitude was bad and I find that I have the HIV virus, I would have to change so that I live longer." In the words of a male community leader in Zambia, "[One] can live for ten years if HIV-positive and look after yourself, or if HIV-negative maintain yourself and abandon [risky] behavior."

All of the focus groups in both communities also discussed the potential disadvantages of voluntary counseling and testing. Reasons given for not wanting to be tested included fear of one's own reaction if results were positive and fear of the reactions of partners, family members, and the community as a whole. The reality that little help is available also weighed heavily on many participants, including two men from Keemba who summed up the situation: "There is no life apart from death" and "Because it [HIV/AIDS] has no cure you know that death is around the corner."

Personal reaction. A range of individual reactions were envisioned, from depression to suicide. Participants in both communities expressed concern that knowing they were HIV-positive would accelerate the process of severe illness and death. One young man from Botswana said, "It may affect that person so much that she will have problems and then the manifestation of the illness will develop much faster." A man in Zambia said, "If you knew your HIV status, it would shorten your life."

Suicide was mentioned by groups in both communities as a potential response to a positive test result. Explanations given as to why HIV-positive individuals would commit suicide included the following remark from a young man in Botswana, "Some people will say that since they are dying, there is no point in prolonging it and so they commit suicide." A male elder thought that people might commit suicide because they "fear 
discrimination. .. . They prefer to die before people despise them." And in Zambia, a breastfeeding participant told the following story:

It happened here in Keemba that the relative to my father was told that he had HIV.... When his parents went for church services on the Sabbath day, he removed all the things in the house, drank poison, and set the house on fire. He died inside the house. He thought it was better to die than to suffer, especially after seeing people with AIDS and the way they suffer without dying early.... Those people await nothing but death.

Focus-group participants in both communities worried that knowledge of HIV-positive status would cause people — in particular men — to intentionally try to infect others. A breastfeeding woman in Botswana expressed the concern that "he would make it worse by infecting everyone, because he does not want to die alone." According to a breastfeeding participant in Zambia, "If men know they have HIV they will give it to others so that others follow him. .. . [He will be] bragging, '62 [women] behind me are coming.,"

Partner's reaction. Men and women in both communities feared that their partners would blame or even leave them if they found out that they had participated in voluntary counseling and testing, especially if doing so resulted in a positive test. In Botswana, participants mentioned concern about physical violence toward women and felt that men would be more likely to abandon women than the other way around. During a discussion about a partner's negative reaction, men and women focused almost exclusively on the reaction of a man when a woman disclosed her HIV-positive status or reported that she had been tested without consulting her partner. In the words of one breastfeeding woman, "She would keep quiet because the man might leave when he finds out I am HIVpositive. So I would keep quiet so that he helps me with the baby."

Male and female focus-group participants in Botswana thought that a woman might get angry with her partner if he was infected, but it was generally believed that she would be 
likely to accept him. As one breastfeeding participant explained, "Women would scold the man a few times and then give in because we women are very soft."

An undercurrent in all discussions about voluntary counseling and testing (particularly regarding disclosure of results and testing of women during antenatal clinic visits) was that the first person to be tested would be blamed for bringing HIV into the relationship. A young pregnant woman in Botswana summed up the opinions of many of her peers by saying, "He will think you brought the disease." In Zambia a man said, "The spouse that goes for an HIV test first is guilty."

Male participants in Botswana confirmed this view by talking about how men would accuse women who got tested, or were HIV-positive, of either being unfaithful or of questioning men's sexual behavior. One young man explained, "He will be thinking that how can his wife betray him like that and to tell him that she has got HIV. Some men ask in an accusing manner with the questions such as: If you are testing, does that mean I have HIV or do the other men you sleep with have it?"

Analysis of study results revealed that fear of a partner's negative reaction was of greater concern in Botswana than in Zambia, which may reflect differences in the stability of partnerships in the two sites. The rate of formally sanctioned marriages is higher in Zambia than in Botswana, where unions tend to be more fluid and shorter-lived. Women in these more fluid types of relationships may justifiably fear a partner's negative reaction because of the relative ease of terminating the relationship.

Family and community reactions. A common concern expressed in all focus groups in both countries was how an HIV-positive person would be treated by the extended family and community. Fear of stigma and discrimination was clearly a major deterrent to seeking voluntary counseling and testing, disclosing one's intent to have an HIV test, or disclosing positive test results. As a man in Botswana explained, "People are afraid to tell others because of the looks they fear that they will get. People are not open about such things." In Zambia, the focus groups also discussed how the family would be 
disappointed, embarrassed, and shamed publicly if a relative was HIV-positive, and that the person would lose respect, access to loans, and votes (if he or she held an elected office).

Discussion of community attitudes and behaviors toward people living with HIV/AIDS provided a means of understanding attitudes about voluntary counseling and testing. Focus groups in both communities had extensive discussions on how people who were either suspected or known to have HIV/AIDS are talked about and treated. This information was revealed in response to a question by moderators about how the community views people living with HIV/AIDS, as well as during the discussions on both voluntary counseling and testing and care and support for people with HIV/AIDS. Groups in both communities portrayed quite negative situations, which helps explain the widespread reluctance to be tested. Participants also reported reactions such as gossip, naming, and blaming, as well as overt acts of isolation. As a breastfeeding woman in Zambia put it, "The majority will denounce you and point fingers at you. At weddings [they] leave you alone, give you your own plate, and make up a song about you."

Examples given in Zambia of teasing and stigmatizing included:

Diarrhea has just walked past.

This one be careful! It's fire! It's fire!

He will make people finish.

She is the killer of the world.

He knows he is not okay, but he is still busy going into other people's wives.

Enda-enda [going, going, gone].

Physical isolation of a person with HIV/AIDS apparently follows gossip and derogatory references. In Botswana, a male participant explained, “They say this person is not supposed to stay with people or share things like the toilet with them." In Zambia, a pregnant woman summed up descriptions by several members of her discussion group: 
"Relatives fear you and segregate you when it comes to eating and do not want to stay with you." In Botswana, many participants talked about how stigma and isolation extend to the children of people living with HIV/AIDS, as described by one man: "The child is teased and rejected by other children who will stop playing with it."

In addition, because community members commonly equate HIV infection with promiscuous behavior, it is often assumed that a person living with HIV/AIDS has engaged in unsanctioned sexual behavior and has brought the illness on him/herself. A breastfeeding participant in Botswana said, "People will be saying that is what you get for bitching around." The idea that many women are unable to protect themselves from infection because of a partner's promiscuous behavior was recognized by female participants in both countries and summed up by a breastfeeding woman in Zambia: "Nothing we can do [can prevent our getting HIV] because it can be brought by unfaithful husbands."

A young pregnant woman in Botswana aptly described the added injustice of facing community stigma based on the assumption of one's "immoral" behavior, when HIV infection was, in fact, the result of a partner's behavior: "When you get AIDS you are ridiculed by society, they laugh at you, they don't regard it as just an illness. You are illtreated, you are no longer related to like before. People think you have been careless, promiscuous. They don't know that AIDS can just come to you at home."

Despite overwhelming evidence from the studies that people living with HIV/AIDS are often treated poorly, it is important to emphasize that many families and individuals in both countries treat people with HIV/AIDS with dignity and compassion. In Botswana, many discussion group participants were able to cite the radio slogans of the National AIDS Control Program, including "A friend with AIDS is still a friend" and that people with AIDS "should be treated the same way as any other person, sharing everything with them." 
Disclosure of test results. Fear of how one might be treated if one is HIV-positive is strong, as reflected in discussions about the difficulty of disclosing test results. In Botswana, mothers were consistently mentioned as the only people to turn to with the news of HIV-positive status. While some participants in Botswana said they would tell their partners, other participants (particularly women) said there was no one they could turn to. As one male respondent explained, "If a person comes from testing and it is positive, they will probably find it difficult to tell anyone.” In Zambia, participants generally seemed to think that individuals would disclose test results to at least one person.

The findings from Zambia revealed a gender differential with regard to both the ability to get tested and disclosure. Participants believed that it is easier for men to get tested and find out their status, and that they can more easily disclose their status to their wives. Women, on the other hand, were perceived to have more difficulty disclosing positive results to their husbands; participants felt women would instead turn to their mothers, female relatives or friends, or health workers.

In addition to questions about disclosure of test results, focus-group participants were asked about making the decision to get an HIV test. In both countries, this discussion focused on women, with a consensus that they should consult their partners first and that not doing so could have negative ramifications. Only two participants, a man and a woman in Botswana, thought that a woman could make the decision to be tested on her own. This finding once again underscores the need to fully involve men in efforts to prevent mother-to-child transmission of HIV because of the influence they have on women's lives.

Delivery of voluntary counseling and testing services. The focus groups also suggested ways to make voluntary counseling and testing "easier to use" with regard to the setting, quality, and public perception of services. In Zambia, only one of the focus groups of women indicated a willingness to go to the Keemba health center for voluntary counseling and testing, while all others emphasized the difficulty of confidentiality within 
the health center service-delivery setting. Similarly, a male participant stated, "Health workers at the health center are [community] residents and will tell others and force you into isolation and to withdraw from the community." Other issues raised in Keemba included the need for privacy, individual contact, and ongoing support. Suggestions for how these needs might be met included not designating a particular day, time, or room for testing in order to increase confidentiality, "normalizing" the process by making it more routine, and persuading more people to be tested for HIV.

The groups in Botswana also discussed the need to make voluntary counseling and testing a more frequent and accepted experience, since, in the words of one participant, "Seeing someone else going for the HIV test is very encouraging." One strategy suggested was having HIV-positive role models talk to groups about how voluntary counseling and testing has improved their lives. Other suggestions were: "Door-to-door education through educators and counselors" and actions by medical staff because "doctors should encourage people to go for the test." The importance of good counseling was raised in both communities. A female participant in Botswana explained that the way in which one copes with a positive result "really depends on what type of counseling you received before the test," while men in Zambia emphasized the importance of "being told nicely" and receiving "support like a pillar" from a counselor. 


\section{Drug Treatment}

AZT has been available in Bontleng since the program to prevent mother-to-child transmission was established in Gaborone in April 1999, while AZT and/or nevirapine is expected to be available in Keemba later this year. With regard to taking drugs, then, the studies included specific questions about AZT in Botswana and more general questions in both communities. One question focused on the prenatal supplements given at antenatal clinics.

In Zambia, focus-group participants had mixed views about taking supplements during pregnancy. Participants in several of the female focus groups thought that taking supplements was beneficial and not at all problematic, as did men and community elders. In-laws were also thought to be supportive, as long as they could be sure that the supplements were not intended for family planning purposes. However, several of the female participants expressed concern about taking supplements because of a belief that they would result in babies that would be too big at birth and thereby make delivery difficult. Additional concerns included the possibility of forgetting doses or getting sick from supplements. In the words of one pregnant woman from Zambia:

Some people discourage from taking drugs saying that the drugs will make the baby too big and can lead to difficult delivery and operation [a cesarean]. As a result, women do not take their drugs, they just store them at home.

In Botswana, most men and elders knew of something available at clinics to help prevent mother-to-child transmission of HIV, but fewer were certain that it was a drug. One male elder said, "Now, I have heard on the radio that there is a medicine or rather the doctors do something to pregnant women so that the virus cannot be transmitted from mother to child." Most women in the Botswana study, on the other hand, not only knew that AZT existed, but mentioned it by name. Knowledge of how the drug is administered and how it works was, however, tenuous. Most women knew that it is given as a tablet, although 
several thought it was administered by injection. Only two women knew that treatment begins at eight months of pregnancy.

When asked specifically how AZT works, responses were quite general. This made it difficult to assess how well women understand the effects of AZT and whether they know that it is not completely effective in preventing mother-to-child transmission. One breastfeeding woman stated emphatically that AZT "prevents the virus from passing from mother to her unborn baby." However, some women used the terms "reduce" and "decrease," rather than "prevent," suggesting that they understood that the probability of transmission would be diminished. Still others put the two types of terms together, causing some confusion with regard to what they knew. For example, one breastfeeding woman stated that AZT "reduces the virus. The child will be born without the virus."

In addition, there was confusion about the effects of AZT. Some participants had a clear understanding that the treatment was not going to benefit the mother directly. In the words of one breastfeeding participant from Botswana, "When we are given talks at the clinic we are taught that it does not mean when a person is HIV-positive they will be cured, but they say they have found some medicine that will protect babies in the mother's womb." Other women expressed anger about this fact, as illustrated by the statement of another breastfeeding participant: "When you are eight months pregnant you are injected to protect the baby, not you."

A few participants indicated a different perception—or perhaps a hope—-that a mother would in some way benefit directly from AZT. Regarding how men view the drug program, one breastfeeding woman from Botswana said, "The men who seem to know about the program say, 'Yeah, it is okay. My wife, if they give you the injection for prevention of transmission from mother to child it means that even you yourself will be cured.'",

Members of two focus groups believed that once a woman stopped taking AZT she would become ill, and perhaps even die because, according to one breastfeeding 
participant, "She starts to lose weight and now shows clearly that she has the virus. She becomes actively ill, or even dies." This belief seemed to stem from the knowledge that AZT works by "decreasing" the virus in the body. In addition, in the words of a pregnant woman, "it also makes you strong" and if AZT treatment is ended, "the HIV will get worse, because when you stop the AZT it means [that] what will be making it less [is now gone]."

Female participants discussed factors that influence compliance with an AZT regimen. Concerns expressed in two of the three female-only focus groups in Botswana were related to possible side effects and whether the drugs could be taken confidentially. Perceived side effects ranged from "it makes them overeat" to "some put them aside because they make them vomit." One breastfeeding woman said, "Some may just take the tablets home and decide not to take them, thinking the tablets have a virus." Only one woman thought that she might forget to take the tablets.

The ease with which women can take AZT without others in the household noticing was debated. A small majority of women thought that taking the drug would be problematic. Only one woman thought that her peers would not even want to take the drugs home for fear that people would notice. Others believed that husbands and partners would notice, but that others would not. Men were more apt to notice because of their proximity, as illustrated by the statement of a breastfeeding woman: "Your man would notice [taking AZT] because you stay with him in the house."

A pregnant Botswanan woman explained, "Even the supplement tablets that pregnant women bring home, the men usually ask us what they are for," while another pregnant participant said, "I bring the tablets home he will ask what they do, one by one saying those brown ones, what do they do." However, some women did not believe that bringing supplements home would be a problem, as indicated by a breastfeeding participant, "I don't think even the man will notice because men don't take too much notice of anything. He would just assume that you have to take them because you are pregnant." 
Learning what community members know and believe about taking supplements or drugs during pregnancy is relevant to the development and implementation of programs to prevent mother-to-child transmission. Some women apparently have trouble taking prenatal supplements (such as folic acid) because of side effects, the tendency to forget to take them, and fears of having very large babies and difficult deliveries. Programs to prevent mother-to-child transmission need to consider how these issues affect the willingness to undergo and comply with an AZT regimen, and, in turn, what is the best way to frame messages about AZT in order to overcome potential barriers.

In addition, the fact that women find it difficult to take drugs without others (particularly partners) noticing again points to the need to gain support from men and community members for programs to prevent mother-to-child transmission because of the influence they have over women's lives and decisions. On the other hand, if AZT can be provided in such a way that it appears to be just another routine prenatal drug, women might not face any questions about taking it. Finally, ongoing monitoring of what the community knows and understands about AZT is necessary to formulate effective education and communication messages and to respond to incorrect assumptions about what the drug is and how it works.

\section{Infant Feeding}

Focus-group participants in both Botswana and Zambia reported that breastfeeding is the norm with regard to infant feeding. In fact, women who do not breastfeed are closely scrutinized by family members and community residents and often pressured to justify their decision not to breastfeed. Participants in both communities mentioned the impracticality of not breastfeeding, noting the difficulty of finding tinned milk and the expense and inconvenience of purchasing and using baby formula. The groups noted the dangers and difficulties of bottlefeeding (e.g., the need for plentiful, clean water and sterile conditions for preparation) as well as the additional cost that this feeding method entails, which could at times result in parents running out of formula. 
Participants in both communities recognized the symbolic significance of breastfeeding, which is widely associated with being a good mother. One young breastfeeding participant in Botswana summed this up: "Breastfeeding means she is a real woman." In addition, all of the focus groups reaffirmed that breastfeeding is the norm not only because of tradition, but also for health-related, practical, and economic reasons. A Botswanan man cited the health benefits for the baby: "We have all been breastfed. We are told breastmilk has nutrients and it is very clean. The bottles are not properly washed and a baby who is breastfed is stronger than the one who is bottlefed. Breastfeeding is very necessary." Women in Zambia expressed the same opinion; one pregnant participant stated, "The first yellowish milk is very important for the growth of a baby. They better not miss it because it has good nutrients."

The strength of the breastfeeding norm, as well as the pressure on women to adhere to it, is reflected in comments made by all of the groups about how women who do not breastfeed are perceived: They are suspected of being bad mothers who do not love their children and who are more concerned about their own needs (e.g., their appearance) than the health of their babies. The most frequently mentioned perception of nonbreastfeeding women is, however, as expressed by a breastfeeding participant in Botswana: "She does not breastfeed so that she can fool around [have sex]." This conclusion was apparently based on taboos that exist in both communities against a woman's being sexually active while she is breastfeeding. A traditional belief in Botswana is that an infant will be harmed if a woman has sex with a man who is not the father of her baby while she is breastfeeding. As one man said, "In our culture breastfeeding means to prevent the mother from sleeping around. . . if they sleep around during breastfeeding they will affect the baby."

Nonetheless, focus-group participants in both study areas noted that a community often recognizes legitimate reasons for women not to breastfeed. This was mentioned more frequently in Botswana, possibly because infant formula is widely available and more affordable there than it is in Zambia. Acceptable reasons included breast diseases (e.g., cancer or lumps), problems with breasts, insufficient production of milk, refusal by a baby 
to breastfeed, the need to return to work, subsequent pregnancy, and HIV infection. ${ }^{11}$ At the same time, despite recognition of these issues, pressure to breastfeed remains strong, and women who choose not to are expected to provide a reason.

In Botswana, in particular, participants emphasized the need for a women to consult several people before opting for bottlefeeding, including, in order of importance: (1) the child's father, since he is often the one who "buys the formula"; (2) the woman's mother, who takes care of her daughter during her daughter's 2-3 months of confinement (known as botsetsi) and who, in the words of a breastfeeding participant, "is the one who is going to look after the baby when she [the mother] is not in"; and (3) in-laws.

The need to justify the decision not to breastfeed, together with the suspicion that HIV infection might be the reason a woman is not breastfeeding, puts HIV-positive mothers in a difficult position. As the incidence of HIV/AIDS increases, it is becoming more common for community members to assume that nonbreastfeeding mothers are indeed HIV-positive. Women who receive formula through participation in programs to prevent mother-to-child transmission are therefore essentially assumed to be making a public declaration of their HIV-positive status. As a male elder in the study community in Botswana said, "They also think that if she is not breastfeeding she must be in the government mother-to-child transmission prevention program. Therefore, she must be HIV-positive. That is what people are afraid of, so people just say let me breastfeed him so that people may not think I am infected." Another man in Botswana stated simply, "Breastfeeding is a common practice. It is therefore difficult on a woman who is HIVinfected."

\section{CONCLUSIONS AND RECOMMENDATIONS}

By listening to individuals, it is possible to gain insight into how to design and deliver interventions that will be effective in saving the lives of adults, children, and infants

\footnotetext{
${ }^{11}$ In Botswana, pregnancy was cited because of the belief that breastmilk from a pregnant mother is harmful to the child and would stunt its growth and development.
} 
worldwide. The studies in Botswana and Zambia underscored how local communities can benefit from the research process through gaining knowledge about HIV/AIDS, motherto-child transmission of HIV, the need to access voluntary counseling and testing, and through confronting such difficult issues as stigma and discrimination against and the care of people living with HIV/AIDS.

The study findings highlight the complex challenges and opportunities posed by prevention programs. The primary conclusion is that such programs have an urgent need for the information and perspectives that emerge from community dialogue about HIV/AIDS and prevention of mother-to-child transmission. While community participation is important for all types of health programs, it is especially critical in the case of prevention of mother-to-child transmission of HIV because program components (i.e., voluntary counseling and testing, treatment, and infant feeding) require women to make difficult decisions. The data collected are evidence that community members have opinions, beliefs, and values that directly affect their decisions about participating in programs to prevent HIV/AIDS and mother-to-child transmission. The effectiveness of such programs can be improved by using community perspectives in both designing and implementing them.

It is clear from the study findings that women who are deciding whether to participate in a program to prevent mother-to-child transmission are clearly influenced by the opinions of their spouses and partners, as well as by those of family and community members. The focus-group discussions in Botswana and Zambia illustrated that spouses and partners influence decisions about HIV testing and treatment and about infant feeding. Parents, inlaws, and other relatives may have a less direct influence on testing and treatment decisions, but are clearly involved in infant feeding practices. The study findings underscore that in order to succeed, programs to prevent mother-to-child transmission of HIV must reach these significant others in women's lives with information, education, services, and support. 
Several study findings show that a prevention program is strongly affected by how the community deals with the HIV/AIDS epidemic. Specific influential factors range from the level of community knowledge about HIV/AIDS to attitudes toward those who are infected. Participants cited stigma against HIV-positive people, the poor treatment of people living with HIV/AIDS, and fears about the availability of care and support as barriers to seeking voluntary counseling and testing. In addition, the extent of HIV/AIDS in a community in part determines infant feeding choices and, to a lesser degree, drug treatment during pregnancy, both of which are public actions that can signal to others that a woman is HIV-positive.

The data revealed that men are less informed than women about HIV/AIDS in general and about mother-to-child transmission in particular. This finding is significant because of the influence that men have on women's lives and decisions. Participants recognized this disparity in knowledge and attributed it to the place and manner in which information is shared, namely by health care providers at antenatal and well-child clinics, where men and elders—who expressed a desire to improve their knowledge—are unlikely to go.

The focus-group discussions illustrated that a powerful and potentially negative relationship exists between misinformation and lack of community dialogue about HIV/AIDS and mother-to-child transmission, stigmatization of people living with HIV/AIDS, and the difficulties faced by programs to prevent HIV/AIDS (e.g., the reluctance of women to participate in programs to prevent mother-to-child transmission). For example, misinformation about how HIV is transmitted leads to the fear and stigmatization of people with HIV/AIDS, who are in turn less likely to share their HIVpositive status with others. This results in a social climate of secrecy and fear, again leading to an escalation of the stigma surrounding the disease and those who are infected. The cycle can be broken by focus-group discussions led by informed moderators, a critical first step in engaging communities in the prevention of mother-to-child transmission. Only when community members begin to interact compassionately with those infected with HIV will such people be willing to be tested for HIV, thereby meeting the prerequisite for participating in a program to prevent mother-to-child transmission. 
Investigating and making use of community perspectives can be the key to the success of a program. As the AIDS epidemic grows, it is critical that programs not be launched without an understanding of what community members think, believe, and desire regarding HIV and programs to prevent mother-to-child transmission. Programs that are designed without this understanding are likely to fail and waste limited, valuable resources at a time when the means of many countries to address HIV/AIDS and motherto-child transmission are already stretched.

Programs will also fail if (1) women are not full participants and (2) women who participate are stigmatized and rejected. In most communities, women lack independence and decisionmaking power and are part of nuclear and extended family systems that have defined roles and expectations for them. Many women are economically dependent on partners, who can sway decisions related to pregnancy, breastfeeding, and HIV testing. Successful programs are designed to take these factors into account. It is clear that the overarching goal of saving young lives while supporting mothers can only be fully realized if communities understand and support women seeking to prevent the transmission of HIV to their infants.

The studies in Botswana and Zambia have yielded many lessons pertaining to education, counseling and testing, and community acceptance and support. We recommend that prevention programs implement the following:

\section{Education on Prevention of Mother-to-Child Transmission}

- Ensure that education strategies should be participatory and create opportunities for open discussion and participant feedback regarding HIV/AIDS and mother-tochild transmission. Focus-group discussions should be considered an essential tool for both research and community education. 
The focus-group discussions conducted in Botswana and Zambia highlighted the lack of community dialogue on many issues critical to effective programs to prevent HIV/AIDS and mother-to-child transmission. This type of forum provides a unique opportunity for participants to gain information and reflect on the complex issues they face as a result of the AIDS epidemic. The fact that most participants in the studies were discussing these issues for the first time indicates that communities have long been passive recipients of prevention efforts rather than active participants in debating and solving the problems that plague them. In addition, efforts to prevent mother-to-child transmission have often lacked the critical component of dialogue.

- Educate community residents on basic anatomy and physiology in relation to pregnancy in order to enhance understanding of the process of mother-to-child transmission.

There are numerous misconceptions about pregnancy and HIV transmission, including the notion that it is not possible for an HIV-positive mother to give birth to an HIVnegative baby. Resolving such misconceptions can help communities understand the purpose of a program to prevent mother-to-child transmission, and thereby enhance participation.

- Create hopeful messages and use positive role models to promote the benefits of voluntary counseling and testing.

Communities with a high prevalence of HIV/AIDS are often characterized by the sense that trying to address the problem is pointless. In the face of such hopelessness, messages should highlight the advantages of being tested, rather than the consequences of HIV infection in infants. This approach is more likely to motivate participation in counseling and testing programs.

- Use strategies that reach men and elders in the community with information and opportunities for discussion about HIV and mother-to-child transmission. 
Men and elders are key decisionmakers in communities regarding counseling and testing and infant feeding. It is critical to help them learn about mother-to-child transmission in order to engage them as partners in prevention. Reaching them requires that educational sessions, materials, and messages be made available beyond the walls of antenatal clinics. Possible alternative sites are primary or outpatient clinic waiting rooms, where discussion of health-related subjects should include information about mother-to-child transmission of HIV. Community outreach is another useful strategy to reach men.

- Educate health providers on the link between HIV and breastfeeding, as well as the risks associated with other feeding practices, to ensure that they can competently and compassionately counsel women about infant feeding options. In addition, it is important to convey to members of the community that programs to prevent mother-to-child transmission assist women in making infant feeding choices and do not dictate one method of feeding over another.

Recent studies and recommendations regarding breastfeeding by HIV-positive mothers are complicated and confusing. Because the knowledge and attitudes of health providers regarding infant feeding affect their ability to assist mothers in making informed choices, it is important to ensure that they have good information and the opportunity to resolve their own questions. Above all, providers must provide emotional support to HIVpositive mothers regardless of the decision they make regarding infant feeding. Where relevant, programs should encourage providers who normally promote breastfeeding to instead counsel HIV-positive mothers about their options. In addition, if community members understand that programs to prevent mother-to-child transmission do not attempt to coerce women into making a specific choice, they may be less likely to assume that women who choose not to breastfeed are HIV-positive. 


\section{Counseling and Testing Services}

- Whenever possible, offer counseling and testing services outside of antenatal clinics.

Although programs to prevent mother-to-child transmission encourage couples to be tested together, the location of testing in antenatal clinics makes it more difficult for men to retain anonymity, since they do not generally attend clinics. In Botswana and Zambia, study participants expressed the fear that the first partner to be tested will be blamed for bringing the infection into the relationship. Thus, if voluntary counseling and testing is available only at antenatal clinics, men will be less likely to seek services, while women who test HIV-positive will be more likely to be blamed for the infection.

- Ensure that community members are not limited to receiving counseling and testing from health workers whom they know personally.

Many health providers play conflicting roles when they serve their own communities. This is particularly evident when they are required to give bad news (e.g., an HIVpositive test result) or to maintain confidentiality. Study participants frequently mentioned the difficulty providers face in sharing diagnoses with patients and violations of confidentiality as barriers to participation in voluntary counseling and testing. Programs to prevent mother-to-child transmission must either find a way to successfully motivate and train providers to give sensitive, competent counseling, education, and support to members of their communities, or use providers who are not closely connected to the communities they serve.

- Train and encourage health providers to discuss the possibility of HIV infection and the benefits of voluntary counseling and testing openly with their clients and to encourage participation in programs to prevent mother-to-child transmission. 
Study participants expressed resentment when they were given inadequate information or false explanations for HIV-related symptoms. Knowledgeable, nonjudgmental, and confident communication between providers and patients is essential to decreasing the stigma of being HIV-positive.

\section{Community Acceptance and Support}

- Address and reduce stigma and discrimination against people living with HIV/AIDS, making it psychologically safer for women to participate in voluntary counseling and testing.

Women faced with a decision about voluntary counseling and testing will be influenced by perceptions of how their families and communities will treat them if it becomes known that they participated in such a program, in particular if they prove to be HIVpositive. Directors and staff of programs to prevent mother-to-child transmission need to recognize the influence that general community attitudes toward people living with HIV/AIDS have on women's participation. They should seek to improve community acceptance of voluntary counseling and testing and community support of people with HIV/AIDS.

- Increase the level of knowledge regarding HIV transmission and care for AIDS patients in order to reduce the fear and isolation of people living with HIV/AIDS.

The many misconceptions about how one becomes infected with HIV (e.g., through casual contact with or caring for an infected person) contribute to the physical and social isolation of people with HIV/AIDS and, in turn, reluctance to be tested. Education about HIV/AIDS and how to safely care for AIDS patients is critical to ending this cycle of ignorance and fear.

- Provide support and services to families to increase their willingness to care for and support relatives with AIDS. 
The sense of hopelessness that stems from the inevitability of death and the heavy burden of care influence the attitudes of family members regarding care for people with HIV/AIDS. Because of the stigma attached to HIV, there is a perception that families who know that the virus is the cause of a relative's illness decrease their provision of care. This attitude undermines confidence by people with HIV/AIDS that they will be adequately cared for when they become ill, which, in turn, increases resistance to finding out whether one is HIV-positive and sharing this knowledge with others. HIV/AIDS programs should include services, such as home-based care, that help alleviate the burden of care on families of people with HIV/AIDS.

- Create ways to receive feedback from community members in order to monitor their understanding and perceptions of programs to prevent mother-to-child transmission, thereby ensuring that misconceptions and problems are addressed quickly.

Community input is valuable not only in the design phase of programs; it is important to gather input periodically from program participants and others after a program is established. Reactions to the way that voluntary counseling and testing services are organized, for example, might result in improvements in the counseling approach used or reinforce the success of what is already in place. 


\section{Acknowledgments}

The studies reported in this paper were conducted through the generous support of Glaxo Wellcome and UNAIDS.

The research was conducted in collaboration with the following partners:

In Botswana

- Society of Women Against AIDS in Africa/Botswana Branch: Sheila Tlou and Koketso Rantona

- Consultants: Ross Kidd (Participatory Education and Evaluation Research) and Samson Sentumo

- Focus-group discussion facilitators: Koketso Rantona, Samson Sentumo, Sonny Mokgadi, Morwalela Modukanele, Sewa Bale, and Kagiso Tlou

In Zambia

- The Mother-to-Child Transmission Research Team in Zambia: Chewe Luo, Margaret Siwale, Catherine Mukuka, Judy Phiri, Joy Banda, and Chipo Mwela

- Consultants: Philimon Ndubani (Institute for Economics \& Social Research, University of Zambia) and Virginia Bond (Zambart Project, School of Medicine, University Teaching Hospital, Zambia)

- Focus-group discussion facilitators: Chilimba Hamavhwa, Mutinta Handongwe, Bentoe Mapulanga, Anne Mutunda, Chipo Mwela, and Eunice Sikatulu

The content of this paper is based on individual study reports from Botswana and Zambia:

Tlou, Sheila, Laura Nyblade, Ross Kidd, Mary Lyn Field-Nguer, Koketso Rantona, and Samson Sentumo. 2000. "Report on formative research on community responses to initiatives to prevent mother-to-child transmission in Bontleng, Gaborone, 
Botswana," unpublished report. Washington, DC: International Center for Research on Women.

Bond, Virginia and Philimon Ndubani in association with Laura Nyblade. 2000. "Formative research on mother-to-child transmission of HIV/AIDS in Zambia: A report of focus-group discussions held in Keemba, Monze, November 1999," unpublished report. Washington, DC: International Center for Research on Women.

The authors gratefully acknowledge the thoughtful reviews, insights, and assistance of Naomi Rutenberg (Horizons) and Claudes Kamenga (Impact). Thanks are also extended to Geeta Rao Gupta, Kathleen Kurz, Anju Malhotra, Nadia Steinzor, Sanyukta Mathur, Cheryl Morden, and Ellen Cerniglia of ICRW for their comments and editing. The authors also appreciate the ongoing input of the Washington Technical Advisory Group members, including Naomi Rutenberg, Claudes Kamenga, Eka Williams (Society of Women Against AIDS in Africa), Jean Baker (Linkages), Linda Sussman (USAID), Jan Hogle (anthropologist and consultant), and Gail Snetro (Save the Children).

In addition, the authors would like to thank Ben Plumley of Glaxo Wellcome and consultant Susan Perl for their support and commitment.

\section{References}

Bond, Virginia and Philimon Ndubani in association with Laura Nyblade. 2000.

"Formative research on mother-to-child transmission of HIV/AIDS in Zambia: A report of focus-group discussions held in Keemba, Monze, November 1999," unpublished report. Washington, DC: International Center for Research on Women.

Dabis, F., P. Msellati, N. Meda, C. Welffens-Ekra, B. You, O. Manigart, V. Leroy, A. Simonon, M. Cartoux, P. Combe, A. Ouangré, R. Ramon, O. Ky-Zerbo, C. Montcho, R. Salamon, C. Rouzioux, P. Van de Perre, and L. Mandelbrot for the DITRAME Study 
Group. 1999. "6-month efficacy, tolerance, and acceptability of a short regimen of oral zidovudine to reduce vertical transmission of HIV in breastfed children in Côte d'Ivoire and Burkina Faso: A double-blind placebo-controlled multicentre trial," Lancet 353(9155): 786-792.

Guay, L.A., P. Musoke, T. Fleming, D. Bagenda, M. Allen, C. Nakabiito, J. Sherman, P. Bakaki, C. Ducar, M. Deseyve, L. Emel, M. Mirochnick, M.G. Fowler, L. Mofenson, P. Miotti, K. Dransfield, D. Bray, F. Mmiro, and J.B. Jackson. 1999. "Intrapartum and neonatal single-dose nevirapine compared with zidovudine for prevention of mother-tochild transmission of HIV-1 in Kampala, Uganda: HIVNET 012 randomised trial," Lancet 354(9181): 795-802.

Shaffer, N., R. Chuachoowong, P.A. Mock, C. Bhadrakom, W. Siriwasin, N.L. Young, T. Chotpitayasunondh, S. Chearskul, A. Roongpisuthipong, P. Chinayon, J. Karon, T.D. Mastro, and R.J. Simonds on behalf of the Bangkok Collaborative Perinatal HIV Transmission Study Group. 1999. "Short-course zidovudine for perinatal HIV-1 transmission in Bangkok, Thailand: A randomised controlled trial," Lancet 353(9155): 773-780.

Tlou, Sheila, Laura Nyblade, Ross Kidd, Mary Lyn Field-Nguer, Koketso Rantona, and Samson Sentumo. 2000. "Report on formative research on community responses to initiatives to prevent mother-to-child transmission in Bontleng, Gaborone, Botswana," unpublished report. Washington, DC: International Center for Research on Women.

UNAIDS. 2000. Report on the Global HIV/AIDS Epidemic. Geneva: UNAIDS.

UNAIDS and WHO. 1999a. AIDS Epidemic Update: December 1999. Geneva: Joint United Nations Programme on HIV/AIDS and World Health Organization.

UNAIDS and WHO. 1999b. HIV in Pregnancy: A Review. Geneva: Joint United Nations Programme on HIV/AIDS and World Health Organization. 